\title{
A classificação biológica: uma aula a partir do diálogo entre a cultura indígena e a história da ciência
}

biological classification: a classroom from the dialogue between indigenous culture and the history of science

la clasificación biológica: una clase a partir del diálogo entre la cultura indígena y la historia de la ciencia

Ana Flavia Dos Santos Licenciada em Ciência Biológicas Anafla_@hotmail.com

\section{Ellen Gonzaga Lima Souza}

Professora Doutora, UFLA, Brasil. Ellenl.souza@ded.ufla.br

Antonio Fernandes Nascimento Junior

Professor Doutor, UFLA, Brasil Toni_nascimento@yahoo.com.br 
RESUMO : Mediante as diversas problemáticas no ensino de ciências e na aprendizagem em geral, muitos estudos tem procurado investigar: quais as perspectivas que podem colaborar para construção de um ensino realmente significativo. Sendo assim, o trabalho tem por objetivo analisar os resultados de prática pedagógica diferenciada aplicada para professores em formação inicial e continuada, de forma a verificar se a uma nova perspectiva pode ser apreendida e utilizadas pelos mesmos no seu dia-a-dia escolar. A atividade foi executada no formato de um Minicurso formativo, utilizando a História da ciência e mitologia indígena para construir um caminho sobre a classificação dos seres vivos, percorrendo as épocas históricas mais discutidas atualmente. Após a execução da atividade prática, os participantes realizaram analises escritas sobre o procedimento, colocando suas perspectivas e impressões sobre a pratica. As falas foram analisadas de acordo com a categorização de Analise de conteúdo qualitativo, onde foi verificada a viabilidade do trabalho executado. As analises foram discutidas evidenciando os resultados da pratica.

PALAVRAS CHAVE: Ensino de Biologia, Classificação Biológica, Interdisciplinaridade.

ABSTRACT: Through the various problems in science teaching and learning in general, many studies have sought to investigate: which perspectives can collaborate to construct a truly meaningful teaching. Thus, the objective of this study is to analyze the results of differentiated pedagogical practice applied to teachers in initial and continuing formation, in order to verify if a new perspective can be apprehended and used by them in their school day-by-day. The activity was carried out in the form of a formative mini-course, using the History of science and Indian mythology to build a path on the classification of living beings, traversing the historical periods most discussed today. After performing the practical activity, the participants performed written analyzes on the procedure, putting their perspectives and impressions on the practice. The speeches were analyzed according to the Categorization of Qualitative Content Analysis, where the feasibility of the work performed was verified. The analyzes were discussed evidencing the results of the practice.

KEY WORDS: Teaching Biology, Biological Classification, Interdisciplinarity.

RESUMEN: Mediante las diversas problemáticas en la enseñanza de las ciencias y en el aprendizaje en general, muchos estudios han intentado investigar: cuáles son las perspectivas que pueden colaborar para la construcción de una enseñanza realmente significativa. Por lo tanto, el trabajo tiene por objetivo analizar los resultados de práctica pedagógica diferenciada aplicada para profesores en formación inicial y continuada, para verificar si una nueva perspectiva puede ser aprehendida y utilizada por los mismos en su día a día escolar. La actividad fue ejecutada en el formato de un Minicurso formativo, utilizando la Historia de la ciencia y la mitología indígena para construir un camino sobre la clasificación de los seres vivos, recorriendo las épocas históricas más discutidas actualmente. Después de la ejecución de la actividad práctica, los participantes realizaron análisis escritos sobre el procedimiento, colocando sus perspectivas e impresiones sobre la práctica. Las palabras se analizaron de acuerdo con la categorización de Análisis de contenido cualitativo, donde se verificó la viabilidad del trabajo ejecutado. Los análisis fueron discutidos evidenciando los resultados de la práctica.

PALABRAS CLAVE: Enseñanza de Biología, Clasificación Biológica, Interdisciplinariedad. 


\section{INTRODUÇÃO}

Para muitos estudiosos não é surpresa que o ensino e as escolas precisam de uma revisão do seu papel na sociedade. Uma escola, independente de disciplinas, burocracias e regras é um espaço de cidadania, tem o compromisso de formar cidadãos capazes de exercer seu papel e modificar sua realidade social. Aas disciplinas escolares, incluindo logicamente Ciência e Biologia, tem por "obrigação" viabilizar este processo, no entanto sabe-se que isso nem sempre acontece.

Os diversos aspectos externos que atingem as escolas e professores acabam por atingir inevitavelmente o processo de ensino e aprendizagem em sala de aula,o sucateamento de recursos, os baixos salários e desvalorização da profissão contribuem para que cada vez mais se esvazie a sala de alua, tanto de professores quanto para alunos. O processo delicado então coloca empecilhos para que a aprendizagem se desenvolva da forma esperada.

O ensino de Ciências e Biologia é conseqüentemente atingido por esses aspectos, e a ciência que por muitas vezes pode contribuir para que o ser humano a compreenda os fenômenos a sua volta e o mundo que cerca perde sua função, podendo se resumir em atividades escolares conteudistas, descontextualizadas propiciando a alienação sala de aula. Na tentativa de suprir essas lacunas do ensino, muitos autores colocam suas propostas na formação inicial e continuada de professores, pois profissionais que realmente sabem a importância do seu papel são um grande passo para a recuperação das falhas de ensino.

A formação de professores no ensino superior tem ganhado força gradativamente, o que revela uma oportunidade de recuperação e reflexão sobre estas fragmentações do ensino e nessa área, diversas temáticas, estratégias e assuntos são propostos com o intuito fazer da sala de aula o ambiente rico e efetivo no ensino. Uma dessas temáticas é História da Ciência e Mitologia indígena, que na amplitude das suas aplicações colocam questões culturais e históricas de forma a perpassar diversos conteúdos, de diversas disciplinas ocasionando uma forma de aprendizado amplo, abrangendo diversos aspectos inclusive a construção do cidadão.

Nessas perspectivas, o presente trabalho visa colocar uma contribuição nesta área, utilizando história da ciência e mitologia indígena para construir os caminhos da classificação dos seres vivos, discutindo também os diversos aspectos que permeiam esta pratica com algumas considerações sobre todo o caminho percorrido, desde o planejamento da atividade até as finalizações com resultados.

\section{A história da ciência no ensino regular e na formação de professores}

Sabe-se que atualmente o ensino tem sido alvo de freqüentes pesquisas a fim de entender 0 processo educativo do Brasil . A disposição das disciplinas regulares e os assuntos discutidos em sala de aula intrigam pesquisadores, que usualmente recorrem a questionamentos - Por que e para que estudar determinada disciplina? - como sendo o eixo principal a ser esclarecido para que aconteça um ensino efetivo dentro da escola básica. O ensino de ciências e biologia então passam pelos mesmos processos de estudo e de questionamentos citados 
anteriormente, e as resposta refletem as necessidades do ensino atual.

Segundo Queiros, Nascimento Junior e Souza (2013)algumas mudanças ocorreram no cenário educacional Brasileiro. Como uma alternativa de garantir o ensino de qualidade forma criadas a LDB/96 (Lei de Diretrizes e Bases da Educação Nacional), as Diretrizes Curriculares Nacionais para o Ensino Médio (DCNEM), os Parâmetros Curriculares Nacionais (PCNs) e (PCN+), que são orientações nacionais que possibilitam uma reforma nos diferentes níveis de escolaridade. Essas possibilidades, no entanto por diversas vezes podem ser interpretadas de forma destorcida, onde se torna reduzido a uma reprodução prática-utilitária dos saberes conquistados pelo homem ao longo da história da humanidade. Essa visão pratica- utilitária de ensino é reflexo da sociedade capitalista, que não permite o aprofundamento $\mathrm{e}$ questionamentos da realidade vigente, empobrecendo a relação de ensino e aprendizagem.

O ensino de ciências, como parte do ensino regular também sofre com as influencias da cultura do capitalismo, o conhecimento aparece como algo pronto, como se não tivesse passado por conflitos políticos,econômicos e sociais entre outros fatores que vão influenciar diretamente na consolidação da ciência .0 ensino pratico-utilitario colocado pelo capitalismo tende a reforçar a o mesmo e processo de entendimento da realidade vivida tem sua importância, porem a utilização somente desta perspectiva não é suficiente, pois não permite o indivíduo extrapolar sua realidade e construir sua autonomia de pensamento(QUEIROS; NASCIMENTO JUNIOR ;SOUZA, 2013)

Nesta perspectiva também, Gastal (2006) e Rezende (2008), colocam que o ensino de ciências é um dever da escola enquanto educadora dos jovens e comprometida em formar cidadãos, e é também direito do aluno aprender a ciência pois é a partir dessas construções que se terá maturidade para entender o mundo a sua volta e a capacidade de interferir no mesmo, o ensino de ciência é um importante elemento formador de cidadania.

Diante dessas considerações, outra perspectiva começa a ser questionada no processo de ensino e aprendizagem : Como ensinar ciências e biologia para que realmente cumpra seu papel na sociedade? E uma das possibilidades amplamente discutidas revela a Utilização da História da ciência como importante elemento que pode suprir a visão pratica utilitária das ciências, colaborando para que o individuo se sinta parte do processo de construção histórica.(GASTAL;2006 , REZENDE;2008 , QUEIROS; NASCIMENTO JUNIOR ; SOUZA ,2013)

A história da ciência, mesmo sendo de um viés interessante para o ensino de ciência, necessita que assuma característica de uma história contextualizada, revelando idéias e pensadores e as influencias que sofriam no seu espaço. Os contextos sociais históricos dos cientistas revelam muito sobre suas pesquisas, colocam a ciência como um produto de construção histórica, humanizando os processos científicos que sempre forma feitos por pessoas e não por gênios intocáveis (GASTAL;2006 ,REZENDE;2008). Esta ciência é capaz de ser interdisciplinar e se entrelaçar fortemente com outras disciplinas, então, a inclusão da história e filosofia das ciência no ensino regular é defendida para uma a aprendizagem emancipadora e critica. (GASTAL;2006 , REZENDE; 2008)

A ciência sempre acompanhada de um contexto é importante também para formação de 
profissionais da área, não só pesquisadores mas evidentemente professores, pois é necessário que o responsável entenda o conteúdo cientifico, o contexto histórico e filosófico envolvido e processo pedagógico para que o ensino seja significativo (GASTAL, 2006 e REZENDE, 2008)

Ainda nessa perspectiva, Reis, Silva e Buza(2012)reforçam a importância da utilização da história da ciências nas diversas disciplinas não como conteúdos factuais, ilustrativos, mais sim como um processo de construção humana, como parte da cultura e resultado de anos de interferências, erros e acertos. Ensinar trazendo essa questões faz aprendizagem rica e emancipadora.

Carneiro e Gastal (2005)Também colocam que a história da ciência pode superar uma crise da educação cientifica, e já é consenso que a história traz diversos benefícios ao ensino. Os parâmetros curriculares nacionais - PCN também reafirmam a necessidade dessa contribuição no ensino, e então é interessante não mais remeter a sua ausência ou presença deste assunto na aprendizagem, mas sim como essa história é construída.

Para a realização de um ensino interdisciplinar, integrador de outras áreas que ajude de forma efetiva a construção de conceitos em sala de aula, é necessário também que os professores saibam abordar a temática na rotina de ensino, então é fato que esse assunto deve integrar os currículos de formação de professores, pois a medida que se compreende e constrói conteúdo em processo de formação, estes aprendizados estarão presentes na sala de aula no ensino básico.(REIS, SILVA e BUZA; 2012). O processo de formação cientifica e lento e esta passível as mais diversas influencias inclusive sociais, política e filosóficas e religiosas do seu momento. (MARTINS; 1998)

\section{Perspectivas da cultura indígena no ensino}

Como dito nos capítulos anteriores, a educação brasileira tem precisado de revisões no que diz respeito a conteúdos e suas forma de construção no ensino, e esta problemática também se entende no que podemos chamar conhecimento cultural que deveria estar entremeado diariamente na rotina da escola básica.

A história que acompanha a os avanços sociais da cultura indígena é muito importante, a lei $n^{\circ}$ $10.639 / 03$ e $n^{\circ} 11.645 / 08$ foram frutos de muita luta de movimentos sociais incluindo nativos indígenas com objetivo de inserir uma visão real dos povos afro-indígenas no ensino, desmistificando as inverdades pouco a pouco disseminada pela sociedade. (KOEPPE, BORGES E LAHM; 2014 , ROCHA; 2012). Os povos indígenas em suas reivindicações, exigiam mudanças no ensino para que os conteúdos revelassem suas identificações socioculturais verdadeiras, pois sabiam que a desinformação era uma realidade nas escolas.(SILVA; 2010)

Apesar da temática indígena e cultural ter tomado mais espaço na educação, ainda sim vê-se uma abordagem minimizada da expressão cultural indígena. Tratar a temática indígena e o índio de forma genérica da margem a diversas descriminações, preconceitos e etc.que podem vistos nos atualmente com as frases emblemáticas como "colonização do Brasil para civilizar os bárbaros e converte-los para sua religião" As manifestações culturais indígenas expressas na educação são na maioria das vezes estereotipadas, alguns autores ainda colocam que a própria 
palavra "índio" no contexto atual pode não representar a pluralidade dos nativos indígenas existentes. (KOEPPE; BORGES; LAHM, 2014; SILVA; 2010). A declaração de Quito, documento feito pelo povo kuna ,em 2004, coloca que os nativos indígenas se auto- denominam Povos Originários, e esta seria a forma mais adequada de contemplar as perspectivas culturais em suas representações, mas o ensino hoje atende a um ponto de vista ocidental, eurocêntrico, dominante, que reforça os preconceitos a respeito da diversidade cultural do país (KOEPPE; BORGES; LAHM, 2014; SILVA; 2010).

Nessa perspectiva eurocêntrica então, os povos originários sempre são "os atrasados" que não dominavam tecnologias e tiveram seus saberes negligenciados, como a manipulação e conhecimento de plantas medicinais, por muito tempo (SILVA; 2010).

Mediante todos os pontos citados anteriormente e passados quase 10 anos de aprovação das leis 10.639/03 e 11.645/08, cabe então realizar um questionamento importante: Como anda a formação inicial e continuada dos professores nas universidades e fora dela com relação às culturas afro- indígenas? (ROCHA; 2012). A falta de formação de professores para atuar no ensino ressalta a lacuna que existe entre as propostas legais e suas aplicações, revelando assim a superficialidade e fragilidade das questões pertinentes à educação brasileira no cenário atual (KOEPPE; BORGES; LAHM, 2014).

As colocações feitas anteriormente então, reforçam a necessidade de programas de formação inicial e continuada para todas as esferas educacionais. Para Rocha (2012) as reflexões a respeito da temática devem ser garantidas nas pesquisas da área da educação e processo de ensino e aprendizagem. Essas práticas necessitam ultrapassar as fronteiras disciplinares, ressignificando as relações étnicas raciais do país. Cabe também as instituições educacionais, incluindo fortemente as universidades, engajar seus estudantes na comunidade a fim de aprimorar sua formação cultural, pois conhecendo novos territórios abrem-se novos caminhos para se atuar junto com as diversas perspectivas culturais pertinentes.

\section{DESENVOLVIMENTO}

O trabalho foi desenvolvido como um desdobramento de uma metodologia de ensino desenvolvida na disciplina de Metodologia do ensino de zoologia da Universidade Federal de Lavras. A atividade se baseou na utilização da história da ciência e mitologia indígena como elemento para compreender a construção da classificação dos seres vivos, com finalidade voltada à formação inicial e continuada de professores.

Antes da aplicação definitiva do minicurso, foi realizado um momento de apresentação a fim de verificar as particularidades a serem corrigidas, então após as alterações realizadas, em outro momento, o minicurso foi aplicado definitivamente para os bolsistas do PIBID Programa Institucional de Bolsa de Iniciação a Docência da Universidade Federal de Lavras, que reúne professores em formação inicial e continuada, com duração de três horas divididos em três etapas:

Primeira etapa: Primeiramente, foi passado para os participantes um mito indígena chamado o "Mito da criação" em formato de animação de vídeo. Este vídeo conta a história do surgimento 
do mundo e dos animais e classificação dos mesmos segundo a perspectiva indígena e após esta apresentação, foi feita uma discussão com os participantes a fim de extrair as ideias desse mito. Nesse momento surgiram muitas contribuições, várias remetendo a como eles explicavam o surgimento do mundo e da vida, como a forma de explicação deles é diferente da que se conhece atualmente na ciência não necessitando da lógica como principal pilar do pensamento. Foram colocadas também diversas questões comparativas a respeito da classificação dos seres vivos, diferenças de concepções entre as explicações indígenas e nossas explicações científicas e a importância de cada uma delas para nossa sociedade, visto a necessidade do entendimento multicultural do país e do mundo. Foi trazido neste momento também que os mitos são expressões que identificam povos e são explicações que não podem ser assemelhadas com explicações científicas. O mito tem como princípio identificar um povo e explicar seus fenômenos. A ciência tem outras preocupações, no entanto, não são melhores nem piores que as percepções mitológicas

Após a discussão, os participantes chegaram a conclusão de que as perspectivas cientificas e mitológicas eram diferentes no contexto da classificação dos seres vivos, a partir daí o espaço de bolsistas foi dividido em 4 grupos, e cada grupo ficou com a responsabilidade de identificar as ideias sobre ciência e classificação dos seres vivos de cada época história (Idade antiga, Media, Contemporânea e Moderna) a partir da leitura de determinadas cartas.

Segunda etapa: A partir deste ponto, cada grupo recebeu um quadro remetendo a cada época histórica, e com a leitura de determinadas características era responsabilidade do grupo discutir e encontrar em qual idade história cada ideia se encaixava de forma mais adequada.

As cartas com ideias foram:

Para relacionar com Idade Antiga.

Principais pensadores: Aristóteles e Platão/ Os seres poderiam ser organizados de acordo com a função que realizavam/ $\mathrm{O}$ ser humano esta no topo da cadeia do ser e as forças naturais são o motor da vida/ Todas as observações destes autores tinham a natureza como teleológica/finalista.

\section{Para relacionar com Idade média:}

Principais pensadores: Santo Agostinho e São Tomás de Aquino/ Deus é o principal elemento dessa época/ Deus Justifica diversas ações, como a forma de governo feudal/ Nesta época não houve grandes avanços científicos, onde ser cientista significava estudar antigos pensadores.

Para relacionar com Idade moderna:

Principais pensadores: Conde de Buffon e Carl Linneu/ A classificação dos seres vivos começa a se estruturara nessa época/ As modificações desta época ocorreram levando a uma revolução mercantilista./ Nesta época a ciência ganha força, evidenciando o rompimento com a época anterior/ Existe a ideia fixista de espécies, e toda uma estrutura de classificação.

Para relacionar com Idade contemporânea:

Principais pensadores: Charles Darwin e Alfred Wallace/Desenvolvimento de teorias da 
biologia com o foco evolucionista/Se inicia a ideia de transformação constante da natureza/O conceito de espécie passa a ser mais trabalhado/As teorias e pensamentos dessa época são as mais aceitas atualmente.

As discussões que surgiram para a relação adequada entre as idéias das cartas e as épocas foram muito ricas, diversos aspectos foram confrontados exigindo o conhecimento prévio dos participantes e comunicação entre os grupos.

Terceira etapa: Após a relação entre essas ideias foi feito uma discussão mais detalhada sobre cada época, contextualizado de forma mais sólida as colocações feitas. As ideias formam bem discutidas durante toda atividade e cada grupo conseguiu colocar as características das cartas em suas respectivas épocas históricas, e consequentemente foi feito um panorama dos conceitos científicos relacionados a classificação dos seres vivos.

\section{RESULTADOS E DISCUSSÃO}

A partir daí, foi solicitado então, que os participantes realizassem uma avaliação sobre a prática, respondendo a pergunta: Qual a importância do minicurso para a sua formação?

Com as avaliações dos participantes, foi possível organizar as ideias de acordo com as categorizações da autora Minayo(2001). 
Tabela 1 - Categorizações realizadas de acordo com as idéias da autora

\begin{tabular}{|c|c|c|}
\hline Categorias & Descrição & Freqüência \\
\hline $\begin{array}{l}\text { "Compreensão da } \\
\text { História da ciência" }\end{array}$ & $\begin{array}{l}\text { Nesta categoria, agrupo-se todas as falas que } \\
\text { de alguma forma se referiram a história } \\
\text { como algo significativo para a compreensão } \\
\text { da ciência e dos conflitos dos seres humanos. }\end{array}$ & $\begin{array}{l}\text { P2,P3,P4, P5, P6, P7, } \\
\text { P8, P9, P10, P11, P12, } \\
\text { P13, P14, P15, P16, } \\
\text { P17, P18, P19, P21, } \\
\text { P22, P24, P25 }\end{array}$ \\
\hline $\begin{array}{l}\text { Metodologia } \\
\text { diferenciada }\end{array}$ & $\begin{array}{l}\text { Categoria que abrange as falas que se } \\
\text { referiram a metodologia do minicurso como } \\
\text { elemento importante para o processo de } \\
\text { aprendizagem. }\end{array}$ & $\begin{array}{l}\text { P1,P3, P8, P11, P13, } \\
\text { P17, P18, P19, P20, } \\
\text { P22, P23, P24. }\end{array}$ \\
\hline $\begin{array}{l}\text { Possibilidades } \\
\text { interdisciplinares }\end{array}$ & $\begin{array}{l}\text { Reúne todas as falas que se remetem as } \\
\text { possibilidades de trabalho interdisciplinar } \\
\text { com a experiência desta pratica. }\end{array}$ & $\begin{array}{l}\text { P1, P2, P8, P14, P23, } \\
\text { P25 }\end{array}$ \\
\hline $\begin{array}{l}\text { Perspectiva social e } \\
\text { cultural Indígena }\end{array}$ & $\begin{array}{l}\text { Esta categoria reúneas falas que colocam a } \\
\text { importância dos assuntos discutidos para } \\
\text { uma melhor apropriação do conhecimento } \\
\text { social e cultural }\end{array}$ & $\begin{array}{l}\text { P2, P8, P16, P20, P21, } \\
\text { P24 }\end{array}$ \\
\hline $\begin{array}{l}\text { Possibilidades } \text { sobre } \\
\text { classificação dos } \\
\text { seres vivos. }\end{array}$ & $\begin{array}{l}\text { Coloca as falas que remetem as } \\
\text { possibilidades de compreender a } \\
\text { classificação dos seres vivos de forma } \\
\text { diferente e efetiva. }\end{array}$ & $\begin{array}{l}\text { P1, P13, P14, P21, } \\
\text { P23, P25. }\end{array}$ \\
\hline
\end{tabular}

Fonte: Do autor

A partir das falas avaliativas, foi possível criar as categorias descritas acima. A primeira categoria "Compreensão da História da ciência" se destaca pela grande quantidade de participantes que a colocou em seus comentários, e esta situação mostra que este foi um elemento notável durante a prática e revela também que não há contato suficiente dos alunos sobre o assunto durante seu processo de formação no ensino universitário.

A história da ciência tem sido justificada por muitos autores, alguns até já relatados na introdução deste trabalho. Assim, para Martins (1998) o ensino de História da ciência é uma ferramenta que pode auxiliar a compreensão dos conceitos científicos do ensino regular, dando os parâmetros para realmente entender o processo de construção científico, como algo lento, passível de erros e acertos e construído por pessoas comuns e não gênios. A perspectiva deste autor se entrelaça com a de outros autores, El-hani, Tavares e Rocha (2004), a ausência da História no processo educativo da ciência reforça o analfabetismo científico, trazendo uma visão fragmentada do processo, como se os pesquisadores fossem elementos separados do contexto social, econômico, político e não sofressem fluências destas questões. Esta 
fragmentação descaracteriza o processo verdadeiro de compreensão da ciência, que na contextualização dos conceitos reflete sua real importância.

Além desta perspectiva também, o ensino de ciências deve ser reforçado no processo de formação inicial e continuada de professores. Pois para Prestes e Caldeira (2009) e Gastal (2006) é necessário que o professor saia bem formado da universidade para que possa atuar em sala de aula, e além da formação de professores os currículos devem exigir e garantir a reflexão destas áreas na formação de ciências. Prestes e Caldeira (2009) ainda reforçam que a história te capacidade de conectar o desenvolvimento da ciência e contribuir para a atuação e formação de futuros professores que interferem diretamente nesta realidade.

Outra categoria destacada é relacionada ao uso de "Metodologia Diferenciada", que abrange as diversas falas relacionadas à metodologia do minicurso. A prática do minicurso se desenvolveu de forma participativa e dinâmica e alguns autores colocam aspectos importantes sobre as praticas. Oliveira (2014) cita em seu texto que o professor gerencia o conhecimento sendo a direção para o caminho para o desenvolvimento das habilidades em sala de aula, é necessário um mediador que esteja ligado aos processos e ao aluno, pois somente assim a aprendizagem será suficiente para a formação de um cidadão atuante no contexto social, pela maturidade que adquire com a experiência. Para Paiva, Maciel e Cosson (2010), os mediadores do conhecimento sempre existiram na vida dos indivíduos e são importantes nos processos de aprendizagem, os mediadores de maneira geral são semeadores do conhecimento que será aplicado por toda vida. Em outra perspectiva de análise, Damiani (2008) coloca que o trabalho em grupo se caracteriza por várias pessoas que interagem e resumem suas práticas a um único resultado, eles estão em colaboração em busca de um resultado único. Nem todas as atividades em grupo são realmente colaborativas, mas deveriam, pois as atividades em conjunto oferecem uma infinidade de possibilidades que não são possíveis de forma individual. Na perspectiva Vigotskyana e Batkthiniana, as interações em grupo podem formar indivíduos que pela imitação de seus iguais, constroem seu conhecimento refletindo a importância deste processo.

Para a autora ainda o ato de pensar e desenvolver aprendizado está intimamente ligada a uma prática social e uma interação dialógica, e é pela participação nas atividades cotidianas, que as pessoas se transformam, construindo seu conhecimento e habilidades. Com o trabalho em conjunto as pessoas começam a compartilhar experiências, conhecimentos, pensamentos e até modelos mentais como resultado da interação. A importância do trabalho em grupo deve ser ressaltada também entre professores, pois pode auxiliar na tomada de decisões, aperfeiçoamento da análise crítica entre outros benefícios que vão enriqueceu sua forma de pensar auxiliando nos desafios do ensino. Esta é uma interação importante que deve ser valorizada, pois a profissão docente acaba sendo solitária, e as horas de interações coletivas são mais voltadas à resolução de problemas burocráticos do colégio (DAMIANI, 2008).

Os benefícios das atividades colaborativas entre estudantes têm sido ressaltados, da mesma forma que entre docentes, por diversos autores. Os trabalhos de Coll Salvador (1994) e Colaço (2004) são exemplos dos que realizam uma análise ampla dos efeitos desse tipo de atividade 
entre estudantes. (DAMIANI, 2008). Para Oliveira (2006) deve-se valorizar a participação dos alunos durante o processo de ensino e aprendizagem, pois são sujeitos atuantes na construção do conhecimento e considerar suas concepções pode auxiliar a atingir o objetivo, que é o ensino dos mesmos.

A outra categoria possível de analisar a partir das falas, retrata as "Possibilidades interdisciplinares" da prática e dos assuntos discutidos. As falas trazem diversas contribuições positivas, colocando a prática como interessante para se atingir a interdisciplinaridade em sala de aula.

Para Augusto et al (2004) as discussões sobre interdisciplinaridade tem ganhado espaço nos ambientes escolares, e esta é uma importante chance para suprir algumas fragmentações inerentes ao ensino. No Brasil, essas perspectivas são refletidas desde 1970, mas com os Parâmetros Nacionais atuais é que estas discussões ganharam força e mais possibilidades de aplicação. Hoje a interdisciplinaridade é vista como necessidade, com a industrialização e as divisões do trabalho a reflexão disso na escola tornou-se o ensino disciplinar e que se difundiu pelo século XX. A compartimentalização do ensino pode colaborar para a compreensão de fatos específicos, gerando alienação e irresponsabilidade dos estudantes, pois sem conhecer todo o contexto não se sentem motivados e responsáveis pelo meio em que vivem. Ainda sim, podemos também colocar que o ensino interdisciplinar não é contra o ensino disciplinar, mas sim é uma forma de contribuir para as necessidades que este ensino não cumpre (AUGUSTO et al.; 2004), ainda são poucos os relatos de uma efetiva inserção da interdisciplinaridade na rotina escola, mas sabe-se que está é uma promissora forma de ressignificar o ensino. A falta de inserção destes projetos no ensino regular pode ser também atribuída às falhas no processo de formação de professores, a formação dentro de uma visão positivista não colabora para que a interdisciplinaridade ocorra desconectando partes fundamentais da formação para aprendizagem (AUGUSTO et al.; 2004).

Outra categoria destacada durante a analise das falas é a "Cultura e importância dos mitos", nessas falas diversos aspectos surgiram com relação ao ensino da cultura indígena, sempre remetendo a importância de ter experiência nesse contexto para poder construir conceitos em sala de aula.

Para Koeppe, Borges e Lahm (2014), a cultura afro- indígena que é garantida Pelas Leis de Diretrizes e Bases e também os Parâmetros Curriculares Nacionais muitas vezes tem dificuldade de ser implantadas, pois a vigência de um ensino que prioriza os conhecimentos europeus sufocam as perspectivas tradicionais do país. Entende-se que esse processo de sobreposição de conhecimentos, colocam as manifestações culturais afro indígena na maioria das vezes como estereotipada e alegóricas, e a partir disso se dá a abertura para a construção de preconceitos, racismos e diversos obstáculos que vão impedir a compreensão da importância desta perspectiva. A classe dominante se reafirma na sociedade com a propagação deste tipo manifestação reprodutora dos contextos errôneos na escola (CARI; 2008).

Neste processo também, a falta de formação inicial e continuada dos professores, não somente de ciências, contribui para o distanciamento entre a lei e sua real implementação. 
Esta recorrente prática pode revelar o descomprometimento das esferas públicas em reforçar um ensino de qualidade, evidenciando assim que o processo educacional hoje é um desafio (CARI; 2008). Para Rocha (2012), os debates que existem na área devem avançar para a garantia da implementação real das discussões cultura na sala de aula, as práticas não devem se prender aos conteúdos específicos, mas devem perpassar as áreas do conhecimento ressignificando as relações étnicas raciais dentro dos conteúdos. As instruções que "garantem" a inserção da perspectiva cultural no ensino são terreno fértil para uma formação de cidadãos que participem e atuem no contexto social, estas medidas também podem ser potencializadas quando o papel da universidade, institutos e escolas também se comprometem a abrir novos territórios que contribuem para a formação de professores e indivíduos que consigam então realizar a preservação do patrimônio cultural e material do Brasil (ROCHA; 2012).

Para Lopes da Silva e Grupioni (1995), muitos são os vestígios que podem ser utilizados em um contexto educativo para se colocar a perspectiva cultural indígena em discussão e os mitos indígenas têm sido estudados por não índios desde a colonização do Brasil, essa tem sido interessantes, pois de alguma forma, se percebe como a cultura eurocêntrica esta implantada atualmente e como ela se posiciona em relação às outras culturas ao redor do mundo. Os mitos então, estudados nesta perspectiva, se colocam como caráter de divulgação da cultura, a intenção é positiva, porém em algumas destas relações se banaliza o processo (LOPES DA SILVA; GRUPIONI; 1995).

É importante ressaltar que visão de igualdades e diferenças entre os povos, muito vistas nos mitos, devem ser o enfoque de atividades docentes, pois são ideias que se refletem em todas as áreas da humanidade. Então, para que o trabalho seja efetivo com a utilização de mitos indígenas na escola é necessário haja uma reflexão sobre as questões culturais envolvidas no contexto do mito, daí se tem uma visão aproximada da concepção original dos mitos. (LOPES DA SILVA; GRUPIONI; 1995).

A contraposição entre mito e a lógica já estava presente nas sociedades antigas, onde Mytos e logos eram representações excludentes. Para os gregos Logos era da ordem lógica em contraposição aos Mytos que estavam na fabulação. Essa dissociação entre lógica e mitologia é que vai explicar muito do que pensamos na sociedade atual. Estas ideias de muito tempo atrás foram semeadas e difundidas a partir do século XIX, e nesta concepção, iniciada pela segregação das ideias desde a Grécia antiga, há somente povos que conseguem fazer ciência e povos que ainda não atingiram este patamar ( LOPES DA SILVA; GRUPIONI; 1995).

Mesmo com essas percepções, os mitos ainda sobrevivem em diversas partes do mundo. Os mitos são produzidos por culturas específicas que expressam um contexto social, são essencialmente questões que retratam situações humanas plurais, apesar da particularidade das suas criações. Nestas perspectivas conclui-se que os mitos não podem ser mais considerados fantasias de histórias infantis, e não são opostas ao "logos", mas sim são formas de pensar que articulam percepções da lógica, cultura, filosofia, e saberes históricos, e é preciso romper com estas imagens que até hoje sobrevivem no ambiente escolar e cotidiano (LOPES DA SILVA; GRUPIONI; 1995). 
Outra categoria retirada das falas dos participantes se refere à construção dos "conceitos relacionados à classificação dos seres vivos". Para muitos participantes em suas falas, houve uma intensa colocação das palavras "conceitos de ciências e biologia" e "conceitos de classificação dos seres vivos" como questões que se constroem no processo da história da ciência. Na verdade, a história da ciência na íntegra, abriga diversas áreas, como física, química, biologia, tecnologias entre outras áreas, sendo assim, nesta prática uma breve história da classificação dos seres vivos é que foi construída, no entanto todas as falas estão contempladas nesta categoria.

Para Santos e Calor (2007) em suas considerações sobre a classificação dos seres vivos, coloca que é claro que a área necessita de um contexto que entrelace as concepções dos alunos com a perspectiva histórica científica, para que assim consiga ser articulada de forma transdisciplinar como proposto pelos currículos. Para o autor ainda, a filogenética proposta pelos documentos curriculares colocam um proposta que articula o contexto filosófico e cientifico, o que seria ideal, mas acontece freqüentemente. Para Rodrigues, Justina e Meglhioratti (2011) a classificação dos seres vivos, ou a sistemática filogenética permite que os indivíduos percebam semelhanças e diferenças entre os seres vivos, numa perspectiva de cunho evolutivo. A comparação que a sistemática possibilita é capaz de diminuir a distancia entre os grupos de seres vivos e contribuir para o ensino de zoologia, botânica entre outros aspectos com possibilidade de abordagem. As estratégias de ensino que utilizam aspectos filogenéticos podem ser interessantes por evitar a memorização de características de determinados grupos facilitando a construção de conceitos (RODRIGUES, JUSTINA E MEGLHIORATTI; 2011).

O estudo da filogenética pode auxiliar na construção do pensamento cientifico, e também é uma importante ferramenta para lidar com as concepções do senso comum trazidas pelos alunos. Essas vertentes podem auxilia na construção do conhecimento dos pilares do conhecimento biológico, como a grande contribuição que esta tem para as questões evolutivas envolvidas (SANTOS; CALOR; 2007). Para as autoras Prestes, Oliveira e Gerda (2009), pode-se dizer que a filogenia está indissociada dos aspectos evolutivos e atrelada fortemente a outras áreas da biologia. $E$ as inverdades do caminho de construção da ciência são facilmente reveladas e discutidas pela história da ciência.

\section{COONCLUSÃO}

A partir da prática, foi possível verificar a importância dos procedimentos para a formação inicial de professores dentro da universidade. Durante o processo foi possível esclarecer diversas duvidas sobre o contexto e a pesquisa especifica possibilitou novos olhares referentes ao ensino de ciências. A prática com os participantes do PIBID possibilitou um aperfeiçoamento da metodologia com as avaliações feitas ao final do processo. Vários pontos formam destacados nas falas avaliativas, e é necessário se debruçar sobre estes comentários para realmente verificar a eficácia do método, no entanto, a primeiro momento o minicurso foi 
efetivo para que alguns aspectos essências fossem mais evidenciados, como o papel da mitologia na sociedade, a importância da historia e filosofia da biologia para o ensino e conceitos e a importância do contato com o grupo e da mediação do professor nos processos de aprendizagem. Assim pode-se considerar que o minicurso atingiu os objetivos propostos inicialmente.

\section{REFERENCIAS BIBLIOGRÁFICAS}

AUGUSTO, T. G. S.; CALDEIRA, A. M. A.; CALUZI, J. J.; NARDI, R. Interdisciplinaridade: Concepções de Professores da Área de Ciências da Natureza em Formação em Serviço. Ciência e Educação, São Paulo, v. 10, n. 2, p. 277-289, 2004

BAPTISTA, G. C. S. A importância da reflexão sobre a prática de ensino para a formação docente inicial em Ciências Biológicas. Ensaio: Pesquisa em Educação em Ciências, v. 5, n. 2, p. 4-12, 2003

BYNUM, W. Uma breve história da ciência. Porto alegre: L\&PM, 2014.

CARI, C. D. O currículo científico com povo indígena Tupinikim: a tomada de consciência dos instrumentos socioculturas. 171 p. Tese (Mestrado em Educação/Currículo)-Pontifica Universidade Católica de São Paulo, São Paulo, 2008.

CARNEIRO, M. H. S.; GASTAL, M. L. A. História e Filosofia das Ciências no ensino de Biologia. Ciência e Educação, Bauru, v. 11, n. 1, p. 33-39, 2005.

CONSELHO INDIGENISTA MISSIONÁRIO. Declaração de Quito, 2004 - Disponível em <http://cimi.org.br/site/pt-br/index.php?system=news\&action=read\&id=506\# >. Acesso em 22 de março de 2017.

DAMIANI, M. F. Entendendo o trabalho colaborativo em educação e revelando seus benefícios. Educar, Curitiba, n. 31, p. 213-230, 2008.

EL-HANI, C. N.; TAVARES, E. J. M.; ROCHA, P. L. B. Concepções Epistemológicas de Estudantes de Biologia e sua Transformação por uma Proposta Explícita de Ensino sobre História e Filosofia das Ciências. Investigações em Ensino de Ciências, Porto Alegre, v. 9, n. 3, p. 265-313, 2004.

GASTAL, M. L. A. Nem heróis, nem vilões: uma história da biologia que ajude a dar sentido ao aprendizado de biologia. Cadernos de Educação, Pelotas, v. 15, n. 26, p. 103-121, 2006.

KOEPPE, C. H. B.; BORGES, R. M. R.; LAHM, R. A. O Ensino de Ciências como ferramenta na reconstrução das representações escolares sobre os povos indígenas. Ensaio: Pesquisa em Educação em Ciências, v. 16, n. 1 , p. $115-130,2014$

SILVA, A. L. GRUPIONI, L. D. B. A temática indígena na escola: novos subsídios para professores de 10 e 20 graus. Brasília: MEC/MARI/UNESCO, 1995.

PAIVA, A. MACIEL, F. COSSON, R. Literatura : ensino fundamental. Brasília: Ministério da Educação, Secretaria de Educação Básica; 2010.

MARTINS, L. A. P. A história da ciência e o ensino da biologia. Ciência \& Ensino, Campinas, n. 5, p. 18-21, 1998. 
MINAYO, M. C. S. Pesquisa Social. Teoria, método e criatividade. 14 ed. Petrópolis: Vozes, 2001.

NASCIMENTO JÚNIOR, A. F.; SOUZA, D. C. A busca das ideias estruturantes da biologia na história do estudo dos seres vivos no século xix. s/d

NASCIMENTO JÚNIOR, A. F.; SOUZA, D. C. Um olhar sobre o estudo dos seres vivos na Idade Média: temas fundamentais da Biologia na Filosofia da Natureza. Theoria, Pouso Alegre, v. 6, p. 20-38, 2011.

NASCIMENTO JÚNIOR, A. F.; SOUZA, D. C. Um Olhar Sobre o Estudo dos Seres Vivos na Revolução Científica dos Séculos XVI E XVII: Uma Contribuição para o Estudo da Construção do Pensamento Biológico. Theoria, Pouso Alegre, v. 5, p. 1-20, 2012.

NASCIMENTO JÙNIOR, A. J.; SOUZA, D. C. Ideias sobre os seres vivos na antiguidade: a procura de temas estruturantes da biologia contemporânea. Theoria, Pouso Alegre, v. 6, p. 72-90, 2014.

OLIVEIRA, S. S. Concepções alternativas e ensino de biologia: o uso de estratégias diferenciadas na formação inicial de licenciados. Educar em Revista, v. 26, p. 52-62, 2006.

OLIVEIRA, L. B.; OLIVEIRA. T. B. Transversalidade cultural: notas sobre a prática de ensino e a temática afro-descendente e indígena nas salas de aula. 2008. (Apresentação de Trabalho/Comunicação).

OLIVEIRA, W. M.. Uma abordagem sobre o papel do professor no processo ensino/aprendizagem. Inesul, Londrina, p. 01 - 12, 30 jan. 2014

PRAIA, J. F.; CACHAPUZ, A. F. C.; GIL-PÉREZ, D. Problema, teoria e observação em ciência: para uma reorientação epistemológica da educação em ciência. Ciência \& Educação, v. 8, n. 1, p. 127-145, 2002

PRESTES, M. E. B.; CALDEIRA, A. M. A. Introdução: A importância da história da ciência na educação científica. Filosofia e História da Biologia, v. 4, p. 1-16, 2009

PRESTES, M. E. B.; OLIVEIRA, P. P. ; JENSEN, G. M. . As origens da classificação de plantas de Carl von Linné no ensino de biologia. Filosofia e História da Biologia, v. 4, p. 101-137, 2009

QUEIRÓS, W. P.; SOUZA, D. C.; NASCIMENTO JUNIOR, A. F. Possibilidades da Filosofia, História e Sociologia da Ciência para superação de uma concepção prática-utilitária da educação científica: caminhos a serem percorridos. Revista Brasileira de Ensino de Ciência e Tecnologia, vol. 6, p. 23-40, 2013.

REIS, A. S.; SILVA, M. D. B.; BUZA, R. G. C. O uso da história da ciência como estratégia metodológica para a aprendizagem do ensino de química e biologia na visão dos professores do ensino médio. História da Ciência e Ensino: construindo interfaces, v. 5, p. 1-12, 2012.

REZENDE FILHO, L. A. C. História das Ciências no Ensino de Ciências: contribuições dos recursos audiovisuais. Ciência em Tela, v. 1, p. 1-7, 2008.

ROCHA, A. C. Desafios para o Ensino de História e Cultura Afro-brasileira e Indígena. In: XVI JORNADA NACIONAL DE EDUCAÇÃO, 2012, Santa Maria, 2012

RODRIGUES, M. E.; JUSTINA, L. A. D.; MEGLHIORATTI, F. A. O Conteúdo de Sistemática e Filogenética em Livros Didáticos do Ensino Médio. Ensaio: Pesquisa em Educação em Ciências, v. 13, p. 65, 2011.

SANTOS, C. M. D. ; CALOR, A. R. Ensino de biologia evolutiva utilizando a estrutura conceitual da sistemática filogenética - II. Ciência \& Ensino, v. 2, p. 1-8, 2007. 
SETUVAL, F. A. R.; BEJARANO, N. R. R. . Os modelos didáticos com conteúdos de genética e a sua importância na formação inicial de professores para o ensino de ciências e biologia. VII ENPEC Encontro Nacional de Pesquisa em Educação em Ciências, v. 7, Florianopolis, Novembro 2009.

SILVA, M. P. A "Presença" dos indígenas nos subsídios didáticos: leitura crítica sobre as abordagens das imagens e textos impressos. Mnemosine Revista, v. 1, n. 2, p. 268-290, 2010.

TUNES, E.; TACCA, M. C. V. R.; BARTHOLO, R. O professor e o ato de ensinar. Cadernos de Pesquisa, São Paulo, v. 35, n.126, p. 689-698, 2005 